\title{
Efficiency of the Alternative Load Path Method to Evaluate the Progressive Collapse Potential of 3D Building under Blast Load
}

\author{
Mohamed Ahmed Galal', Atul Krishna Banik ${ }^{2}$ \\ ${ }^{1}$ National Institute of Technology, Durgapur \\ Mahatma Gandhi Rd, A-Zone, 713209, Durgapur, West Bengal, India \\ maga.15ce1513@phd.nitdgp.ac.in \\ ${ }^{2}$ National Institute of Technology, Durgapur \\ Mahatma Gandhi Rd, A-Zone, 713209, Durgapur, West Bengal, India
}

\begin{abstract}
- the work in the progressive collapse of three-dimensional composite buildings quite limited due to the cost and difficulties of the full-scale experimental tests and the complexity of the modelling technique. Researchers and design engineers are following The Alternative Load Path method (ALP) recommended by GSA and DoD guidelines to mitigate the progressive collapse potential. The commonly used ALP method, which considers as a threat-independent methodology, taking into account single column removal scenarios only regardless of the threat load type. This paper investigates the efficiency of the ALP to determine the progressive collapse potential of 3D composite building when subjected to $500 \mathrm{~kg}$ of TNT. Two-stage nonlinear dynamic analysis of 3D composite 9-story building with top and seat double web angle connection is carried out. In the first stage of analysis the axial load carried by the columns under gravity load is calculated. The second stage devotes to find out the number of columns likely to be involved in the progressive collapse using the damage index criteria through three-step of loading. A precise analysis is implemented to find out the effect of column location in the remaining capacity of the column. The influence of the boundary condition on the column response under blast load is highlighted. The results show that the ALP methodology is not usually conservative and may be more than one column wiped out under $500 \mathrm{~kg}$ of TNT which may be carried by a small vehicle. The commonly used damage criteria (stability, yielding and fracture) cannot capture the realistic damage of axial load bearing column, and the damage index which is related to its global behaviour has to be used. The structure response drastically increased when two columns removed at a time under blast load compared to the single column removal recommended by ALP of the DoD.
\end{abstract}

Keywords: Progressive collapse, nonlinear dynamic, semi-rigid connection, Alternative load Path, composite building, damage index, blast load.

\section{Introduction}

Progressive collapse phenomena define as the failure of one or more key load-carrying elements either accidentally or intentionally which leads to the collapse of the entire structure or portion of it. The main reasons for progressive collapse refer to extreme loading like blast, bomb gas, severe earthquake, fire, vehicle or aircraft impact or design and construction errors. The progressive collapse takes place when one column removed, and the load carrying by that column transferred to the adjacent columns through flexural elements. If the transferred load is more than the capacity of the nearby elements it fails and the process goes on till the whole building collapse entirely or partially.

England is the first nation to explicitly consider the progressive collapse potential in their building code and design specifications after the proportional collapse of Ronan Point building in London on 1968 due to gas bomb in the kitchen corner in the $18^{\text {th }}$ floor level of 22-story RC building [1]. 911 of the World Trade Centre towers in New York City is the most catastrophic progressive collapse event which lead to 2745 loss of lives and 245 emergency cases due to aircraft impact followed by fire [2].

Most of the work carried out so far in the area of progressive collapse is devoted to 2D rigid jointed steel frames whereas the slab and the semi-rigid characteristic of beam-to-column connection are ignored to avoid the complexity of modelling technique and the time needed to complete the analysis. Marjanishvili and Agnew [3] addressed the advantage and disadvantage of four analysis procedures, Linear Static, Nonlinear Static, Linear Dynamic and Nonlinear Dynamic for the 
rigid jointed 3D building without considering slab contribution using SAP 2000 [4] FE tool. It is concluded that progressive collapse is a highly nonlinear dynamic event as the collapse occurred beyond the elastic limit and the sudden removal of the column is a dynamic phenomenon.

Galal et al. [5] present a comprehensive study of the behaviour of 3D steel-concrete composite building under column removal scenarios. Nonlinear dynamic analysis of 9-story building with three different type of semi-rigid connection is carried out using ABAQUS FE tool. It is found that the slab improved the progressive collapse resistance and the response (vertical displacement) is decreased to around $45 \%$ compared to a 2D frame. New retrofitting schemes are presented which may help the design engineers to mitigate the progressive collapse resistance by increasing the connection rigidity and placed additional rebars in the slab.

ALP method is a threat-independent approach, and its only consider one column removal regardless of the threat amount and type. Sadek et al. [6], Kwasniewski [7], Khandelwal et al. [8], Alashker et al. [9], Alashker et al. [10] and Galal et al. [5] present a great effort and study the progressive collapse potential of different type of structures under column removal scenarios following the ALP approach recommended by GSA 2003 [11] and DoD 2009 [12]. In spite of the ALP method, is widely accepted and commonly used, but it is still doubtful as it is assuming only one column removal scenario. This study investigates the possibility of removal more than one column under heavy blast load.

This paper presents a nonlinear dynamic progressive collapse analysis of 3D 9-story composite building when subjected to $500 \mathrm{~kg}$ of TNT explosion material. The slab and connection rigidity are considered in the analysis to capture the realistic behaviour of building under progressive collapse event. The number of columns likely to be involved in the progressive collapse analysis is determined through two-stage of analysis. In the first stage of analysis 1.2DL + 0.5 LL gravity load is applied in the slab in each floor level as recommended in DoD 2009 [12]. The axially applied force carried by each column is found out under the gravity load. The second stage of analysis is devoted to determining the damage index of the column under a particular blast scenario. The second stage contains three-step of analysis, the axial load carried by the column which calculated from the first stage of analysis is applied in the first step of the analysis. Then blast load is applied in the front flange of the column as pressure time history where the maximum overpressure and duration time are defined based upon the amount of charge and the stand-off distance. The last step is carried out for the damage column at the end of the blast analysis. A push-down analysis is developed in the third step of analysis to find out the remaining axial capacity of the damage column at the end of the blast analysis. The challenge herein is how to consider the permanent deformation and the degradation of material properties in the begging of the push-down analysis. To overcome that obstacle, restart analysis is carried out using ABAQUS [13] FE software at which the outcomes of the first and second steps of analysis considers as an initial condition in the begging of the third step of the analysis. Hence, the critical stand-off distance of a particular blast scenario can be found out using the damage index criteria. To find out the remaining capacity accurately the column has to be defined as a solid element.

The efficiency of the ALP method which recommends a single column removal only is addressed by comparing the number of column involved in the progressive collapse of the proposed model of analysis. Additional study is carried out to highlight the effect of axial load and boundary conditions in the response of steel column under blast load.

\section{Development of the Numerical Model}

9-story 3D steel-concrete building early used by Marjanishvili and Agnew [3] and Galal et al. [5] is considered herein for the progressive collapse analysis. The building contains 3-bay in the short-side direction and 6-bay in the long-side direction $9.75 \mathrm{~m}$ and $8.25 \mathrm{~m}$, respectively. The uniform story height is $4.3 \mathrm{~m}$ each. All frames in the long-side direction and the perimeter frames in the short-side direction are moment resistant frame with TSD connection, and the other frames are gravity frame with pin connection. The building cross sections and arrangement of the rebar are presented in details in Galal et al. [5] and are not repeated herein for clarity. A 3D view of the building is shown in Fig. 1 (a) while the slab is not shown for clarity.

1.2 DL + 0.5 LL is applied on the concrete slab at each story level where the DL includes the weight of $90 \mathrm{~mm}$ concrete slab with $19.7 \mathrm{kN} / \mathrm{m}$ weight of the perimeter wall and LL is assumed to be $1.9 \mathrm{kN} / \mathrm{m}^{2}$. The elastic modulus of steel and concrete material is $2.1 \times 10^{5} \mathrm{~N} / \mathrm{mm}^{2}$ and $2.8 \times 10^{3} \mathrm{~N} / \mathrm{mm}^{2}$. The material nonlinearity is defined using a bilinear elastic-plastic model with 5\% strain hardening and damage plasticity model is selected for concrete material.

B31 element is used to define steel beams and columns, S41 shell element is selected to define the slab and the reinforcements are defined through the rebar option available in ABAQUS library. The beam to beam and beam to 
column connections is simulated using a nonlinear connector element Joint + Rotation for pin connection and Slot + Rotation for semi-rigid connection. The interaction between the slab and steel beam is simulated by rigid tie constraint.

The widely accepted polynomial model developed by Frye and Morris [14] is followed to determine the moment-rotation relation (Fig. 1 (c).) of the TSD connection as follows:

$$
\theta=\mathrm{C}_{1}(\mathrm{KM})+\mathrm{C}_{2}(\mathrm{KM})^{3}+\mathrm{C}_{3}(\mathrm{KM})^{5}
$$

For TSD connection, $\mathrm{C}_{1}=2.23 \times 10^{-5}, \mathrm{C}_{2}=1.85 \times 10^{-8}$ and $\mathrm{C}_{3}=3.19 \times 10^{-12}$ and $\mathrm{K}$ is given by the following equation:

$$
\mathrm{K}=\mathrm{d}^{-1.287} \mathrm{t}^{-1.128} \mathrm{t}_{\mathrm{c}}^{-0.415} \mathrm{l}_{\mathrm{a}}^{-0.694} \mathrm{~g}
$$

Where $t, d, t_{c}, l_{a}$ and $g$ are top and seat angle thickness, depth of the beam, web angle thickness, length of the top and seat angle and distance from the top or seat angle bolt to the beam flange, respectively as shown in Fig. 1 (c).

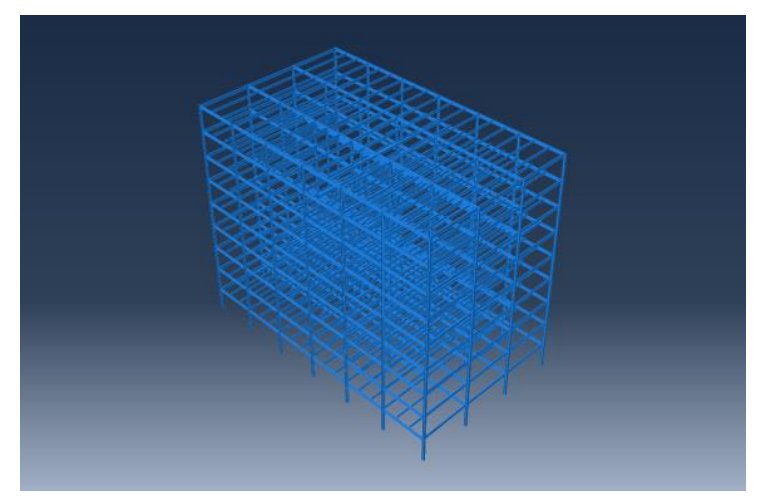

(a)

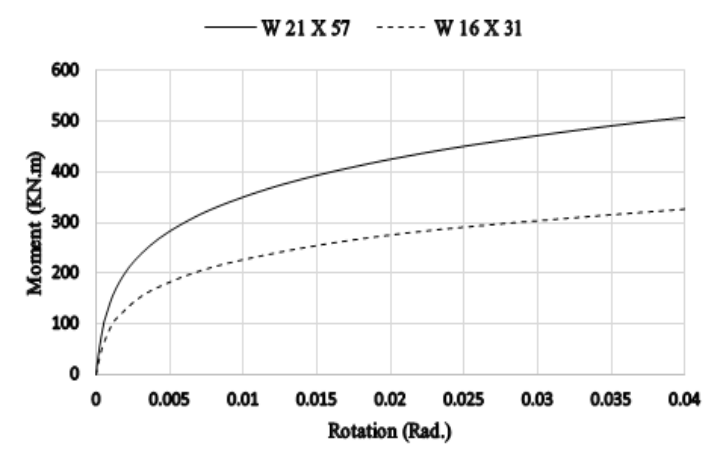

(b)
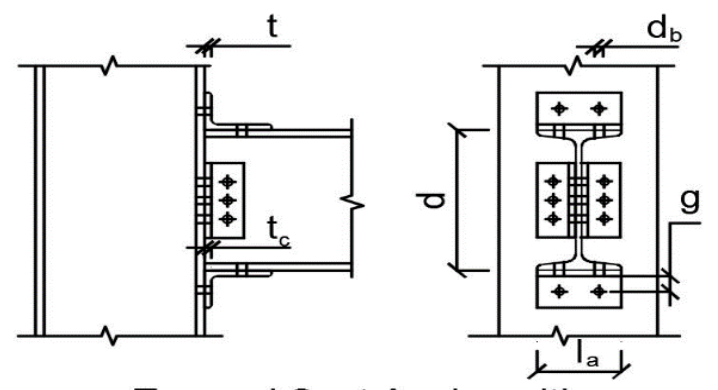

Top and Seat Angles with Double Web Angles Connection

(c)

Fig. 1: a) 3D view of the building, b) moment-rotation curve for TSD connection and c) TSD connection details.

\section{Progressive Collapse Study of 3D Composite Building under Blast Load}

This part of the study presents a nonlinear dynamic two-stage analysis of 3D steel-concrete composite under $500 \mathrm{~kg}$ of TNT. The first stage of analysis is carried to find out the axially applied force in the columns element due to the gravity load $1.2 \mathrm{DL}+0.5 \mathrm{LL}$. The second stage of analysis is developed to find out the remaining axial capacity of the damage column and the corresponding damage index. Fig. 2 describes the load time history of the three-step analysis implemented in the second stage, and the procedure is summarised as follows: 
Step-1: the axial load obtained from the first stage applied gradually in the top of the individual column during 0.5 sec. till reaching to the actual load then kept constant till $2 \mathrm{sec}$. (the end of the explicit dynamic analysis step).

Step-2: once the gradually axial load applied in the top of the column reach its actual value at time 0.5 sec., the blast load applied at the front face of the column web as a pressure time history triangular function. The duration of the blast load and peak over-pressure value are depended only on the charge amount, detonation material type and stand-off distance of the explosion.

Step-3: restart analysis is carried out at the end of the blast analysis step where the permanent deformation and material degradation is considered as an initial condition in the beginning of step-3. The axial load applied again to get the remaining axial capacity of the damage column. To achieve that a downward axial displacement is applied at the top face of the damage column using displacement-control approach. The load-displacement curve of the post-blast column is obtained and the residual capacity of the steel column is found out.

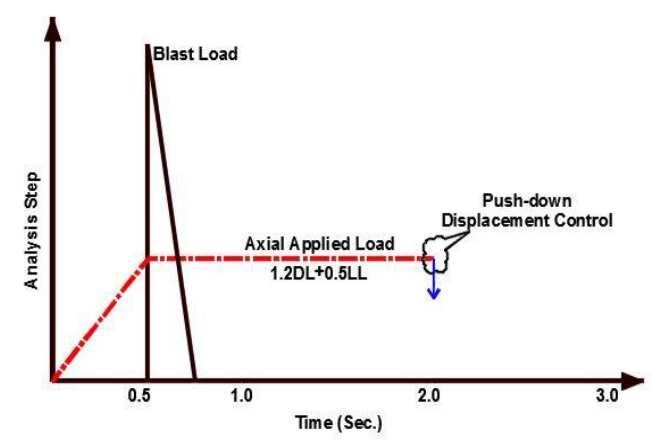

Fig. 2: Load time history of the three steps analysis.

\subsection{Determine the Damage Index of the Column and the Corresponding Critical Stand-off}

Shi et al. [15] define the principles which should be satisfied to find out the damage criterion of a particular column under blast and summarised as follows:

1. The availability of calculating the column damage from all possible damage mode (shear, flexible and combined).

2. It should be related to the global properties of the column and not only for the material properties reduction.

3. Ease of determination the column conditions either experimentally or numerically.

None of the commonly used damage criterion (stability, yielding and fracture) satisfied the above-mentioned principles. Hence, the work of that study following the damage index to find out the damage level of any column when subjected to blast load according to the following equation:

$$
\mathrm{D}=1-\frac{\mathrm{P}_{\mathrm{N}-}^{/} \text {residual }}{\mathrm{P}_{\mathrm{N}-}^{\prime} \text { design }}
$$

Where $\left(\mathrm{P} / \mathrm{N}_{-}\right.$residual) is the residual axial carrying capacity of the damage column under a certain blast scenario which calculated from the three-step of analysis, and $\left(\mathrm{P}^{\prime}{ }_{\mathrm{N}_{-}}\right.$design) is the design axial capacity and it can be obtained numerically or analytically. Column $\mathrm{C}_{1}$ as shown in Fig. 3 on the ground floor is selected as an illustrated column to find out the damage index and the corresponding critical stand-off distance under $500 \mathrm{~kg}$ of TNT.

$\mathrm{D}$ is the damage index, $\mathrm{D}=(0$ to 0.2$)$ low damage, $\mathrm{D}=(0.2$ to 0.5$)$ medium damage, $\mathrm{D}=(0.5$ to 0.8$)$ high damage and $\mathrm{D}=(0.8$ to 1$)$ collapse. The column is considered as a damage column and has to be removed in the collapse analysis when the damage index reach the collapse limit between 0.8 and 1 . 


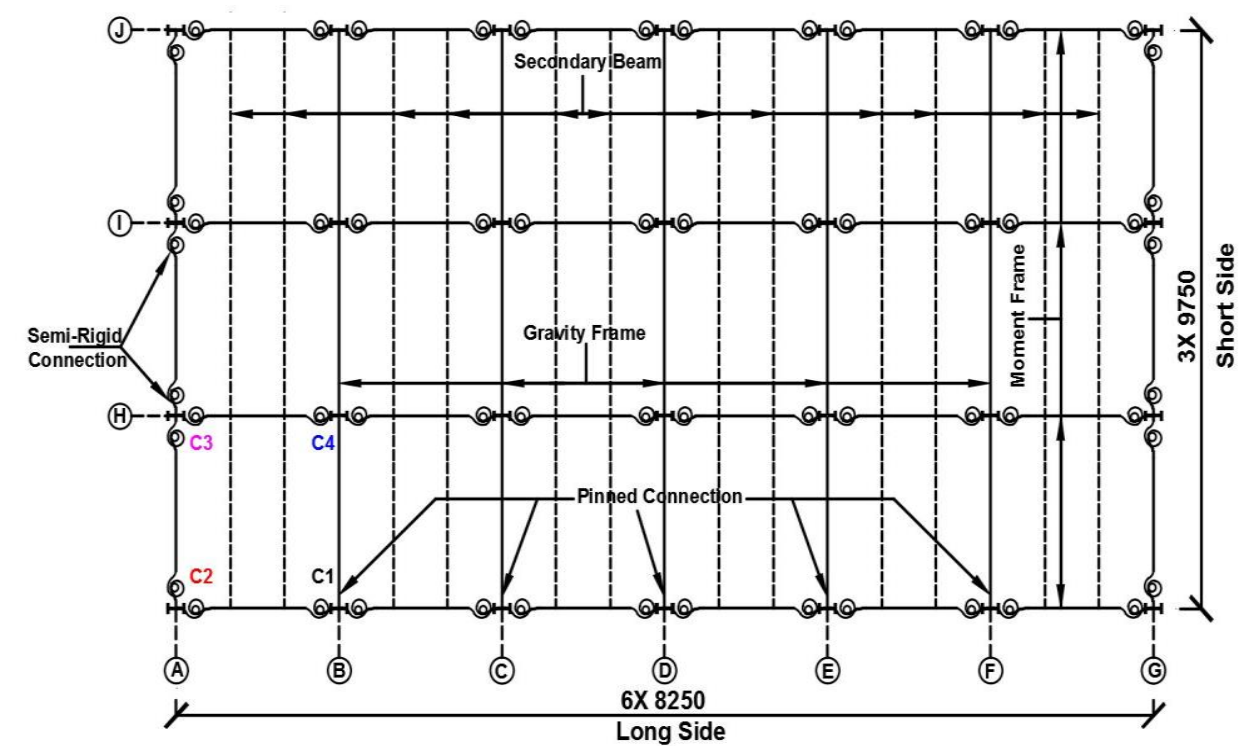

Fig. 3: Plan view showed the location of the selected four columns of the analysis.

\section{Results and Discussion}

Table 1 shows the residual axial capacity and the corresponding damage index of column $\mathrm{C} 1$ for different stand-off distance under $500 \mathrm{~kg}$ of TNT. Fig. 4 depicted the relationship between the stand-off distance and the corresponding damage index for $\mathrm{C} 1 \mathrm{under} 500 \mathrm{~kg}$ of TNT. It is found that the critical stand-off distance corresponding to 0.8 damage index is 5.35 $\mathrm{m}$ which means if $500 \mathrm{~kg}$ of TNT charge is exploded near to the building, all the columns located in the critical zone of 5.35 $\mathrm{m}$ would be collapsed at the same time.

Table 1: Damage index and residual axial capacity for column $\mathrm{C} 1$.

\begin{tabular}{|c|c|c|}
\hline $\begin{array}{c}\text { Stand-off Distance } \\
(\mathrm{m})\end{array}$ & $\begin{array}{c}\text { Residual axial capacity } \\
(\mathrm{kN})\end{array}$ & Damage index \\
\hline 5 & 1598 & $\mathbf{0 . 8 4}$ \\
\hline 5.5 & 2367 & 0.77 \\
\hline 6 & 2737 & 0.73 \\
\hline 7 & 3919 & 0.62 \\
\hline 8 & 4860 & 0.53 \\
\hline
\end{tabular}

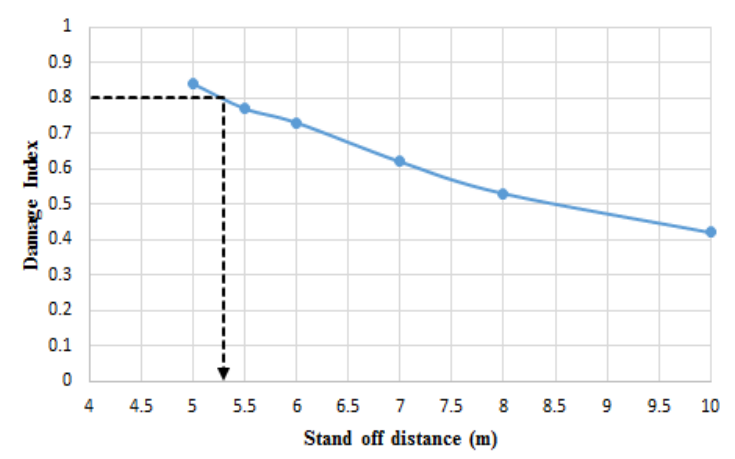

Fig. 4: Critical stand-off distance of column C1. 
For comparison purpose, the critical stand-off distance of four columns (C1, C2, C3 and C4) as shown in Fig. 2 is investigated to highlight the effect of the column locations and the actual axial applied load on the damage index under $\mathrm{kg}$ of TNT. Fig. 5 shows the critical stand-off distance for different column locations and it is clear that the more axial load on the column the more critical stand-off distance.

An additional study is carried out to find out the influence of the column boundary condition in the response under $500 \mathrm{~kg}$ of TNT with $10 \mathrm{~m}$ stand-off distance. Fig. 6 shows the horizontal time history in the middle of column C1 with pinned and fixed boundary condition. Maximum horizontal displacement decreases about 50\% (from $24.28 \mathrm{~mm}$ to 12.06 $\mathrm{mm}$ ) when a fixed boundary condition is considered as compared to the pinned connection.

A comparison between the building response using the ALP (one column removal only in the corner) and blast analysis under $500 \mathrm{~kg}$ of TNT (two columns removal at the corner) located horizontally $4.15 \mathrm{~m}$ far from the left corner and $2 \mathrm{~m}$ vertically far from the front façade as shown in Fig. 7. The results show that the vertical displacement drastically increased when blast analysis is implemented and the acceptance criteria are satisfied under the ALP and not satisfied under the blast load.

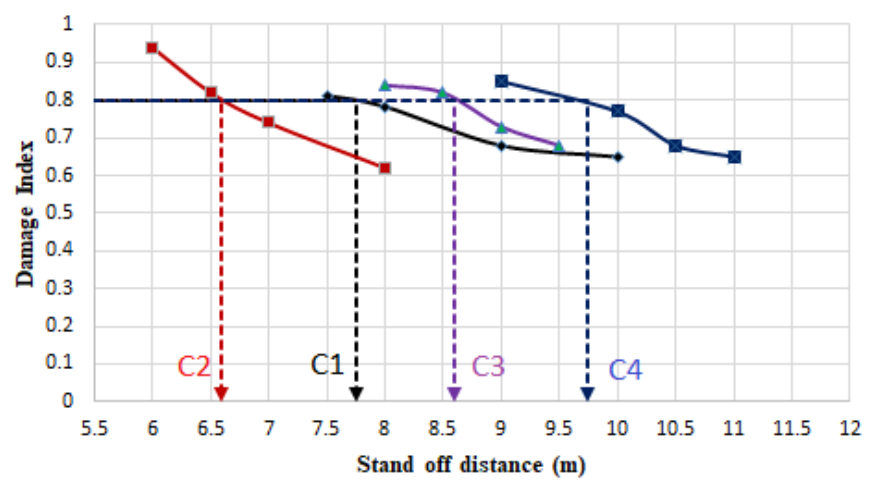

Fig. 5: Critical stand-off distance of column C1.

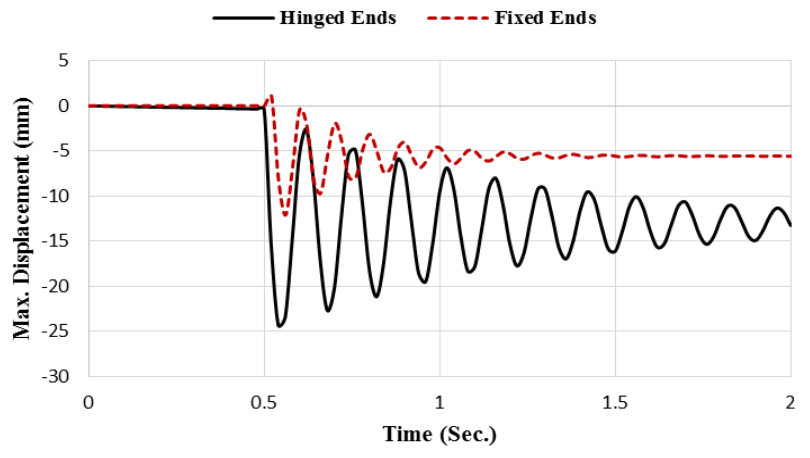

Fig. 6: maximum horizontal displacement in the middle of column $\mathrm{C} 1$ under $500 \mathrm{~kg}$ of TNT with $10 \mathrm{~m}$ stand-off distance. 


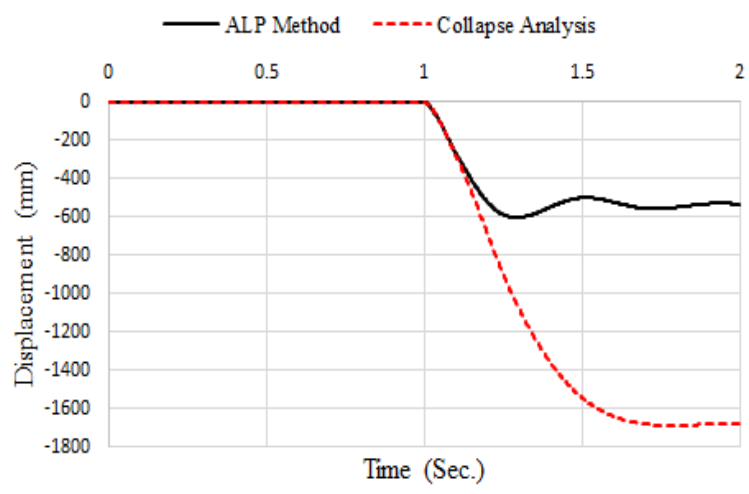

Fig. 7: Vertical displacement time history just above the point of the removed column.

\section{Conclusion}

This paper investigates the efficiency of the commonly used ALP approach recommended by GSA and DoD guidelines to evaluate the progressive collapse potential under $500 \mathrm{~kg}$ of TNT donation material. Two-stage nonlinear dynamic analysis is carried out for a 3D composite 9-story building. The slab contribution, connection rigidity, material nonlinearity and geometry nonlinearity are considered to capture the realistic behaviour of the building under progressive collapse. Beam to column connection is simulated using nonlinear connecter, and the slab and beam interaction is defined using rigid tie constraint. The number of columns likely to be involved in the progressive collapse analysis is decided using the widely accepted damage index criteria. Three steps analysis is implemented using the restart analysis to consider the permanent deformation and material degradation of the damage column under blast load as an initial condition at the beginning of the push-down analysis to precisely find out the remaining axial capacity of the damage column. Based on the results of this study the following findings is summarised as follows:

1. The commonly used ALP method is not usually conservative and nonlinear dynamic analysis taking into account the threat type is needed.

2. Under $500 \mathrm{~kg}$ of TNT, the critical stand-off distance is found $5.35 \mathrm{~m}$ which means all the columns located in the critical zone of $5.35 \mathrm{~m}$ may be wiped out simultaneously when the blast took place.

3. The critical stand-off distance is highly affected by the column locations due to the difference in the axially applied load on the columns.

4. The column maximum horizontal displacement in the blast load direction is improved when fixed boundary condition is considered instead of pinned boundary condition.

5. The maximum vertical displacement at the point just above the point of the removed column is drastically increased when the blast load is considered compared to the threat-independent ALP.

\section{References}

[1] C. Pearson and N. Delatte, "Ronan Point Apartment Tower Collapse and its Effect on Building Codes," Journal of Performance of Constructed Facilities, vol. 19, no. 2, pp. 172-177, 2005.

[2] V. R. Kodur, "World Trade Center disaster-Innovations for improved fire safety in buildings," Journal of Disaster Advances, vol. 1, no. 3, pp. 43-50, 2008.

[3] S. Marjanishvili and E. Agnew, "Comparison of Various Procedures for Progressive Collapse Analysis," Journal of Performance of Constructed Facilities, vol. 20, no.4, pp. 365-374, 2006.

[4] SAP2000. Version 14, Computers and Structures, Inc., Berkeley, Calif.

[5] M. A. Galal, M. Bandyopadhyay and A. K. Banik, "Vulnerability of three-dimensional semi-rigid composite frame subjected to progressive collapse," Journal of Performance of Constructed Facilities, 2018.

[6] F. Sadek, S. El-Tawil and H. S. Lew, "Robustness of Composite Floor Systems with Shear Connections: Modeling, Simulation, and Evaluation,' Journal of Structural Engineering, vol. 134, no.11, pp. 1717-1725, 2008. 
[7] L. Kwasniewski, "Nonlinear dynamic simulations of progressive collapse for a multi-story building," Engineering Structures, vol. 32, no. 5, pp. 1223-1235, 2010.

[8] K. Khandelwal, S. El-Tawil, S. K. Kunnath and H. S. Lew, "Macro-model-based simulation of progressive collapse: Steel frame structures," Journal of Structural Engineering, vol. 134, no. 7, pp. 1070-1078, 2008.

[9] Y. Alashker, H. Li and S. El-Tawil, "Approximations in progressive collapse modelling," Journal of Structural Engineering, vol. 137, no. 9, pp. 914-924, 2011.

[10] Y. Alashker, S. El-Tawil and F. Sadek, "Progressive collapse resistance of steel-concrete composite floors," Journal of Structural Engineering, vol. 136, no. 10, pp. 1187-1196, 2010.

[11] GSA 2003, "GSA Guidelines for Progressive Collapse Analysis," USA. General Services Administration.

[12] UFC (2009), "Design of buildings to resist progressive collapse," USA, Department of Defense (DoD). Unified Facilities Criteria.

[13] ABAQUS. Version 6.14 (Computer software). Pawtucket, R.I., Hibbit and Karlsson, Sorensen.

[14] M. J. Frye and Morris G.A., "Analysis of flexibly connected steel frames," Canadian Journal of Civil Engineering, vol. 2, no. 3, pp. 280-291, 1975.

[15] Y. Shi, H. Hao and Z. Li "Numerical derivation of pressure-impulse diagrams for prediction of RC column damage to blast loads." International Journal of Impact Engineering, vol. 35, pp. 1213-1227, 2008. 